\title{
种植密度对夏玉米茎秆维管束结构及茎流特性的影响
}

\author{
冯海娟 $^{1}$ 张善平 ${ }^{1}$ 马存金 ${ }^{1}$ 刘 鹏 ${ }^{1, *}$ 董树亭 ${ }^{1}$ 赵 斌 ${ }^{1}$ \\ 张吉旺 $^{1}$ 杨今胜 $^{2}$
}

${ }^{1}$ 作物生物学国家重点实验室 / 山东农业大学农学院, 山东泰安 $271018 ;{ }^{2}$ 山东登海种业股份有限公司, 山东莱州 261448

摘 要: 选用不同耐密型品种农大 108 和郑单 958, 设置 3 个种植密度, 研究了种植密度对夏玉米基部第 3 茎节维管 束显微结构和茎流速率的影响。结果表明, 随种植密度增大, 两品种基部茎节的横截面积、大小维管束数目和面积均 显著减小, 并导致总维管束数目和面积减小。两品种对种植密度的敏感度存在显著差异, 农大 108 比郑单 958 受高密 度影响更大。种植密度增加后, 两品种茎流速率及 8:00 至 17:00 的总茎流量均显著减小, 其中郑单 958 的降幅小于农 大 108; 茎秆维管束的运输效率均有所提高, 郑单 958 的升高幅度大于农大 108。相关分析表明, 两品种 8:00 至 17:00 的总茎流量与基部茎节的大维管束总面积呈显著正相关。郑单 958 具有在较高密度下较大幅度提高维管束运输效率 的能力, 表现出在维管束结构、茎流速率、总茎流量及运输效率上的优势, 这可能是其具有较强耐密性, 密植后仍能 获得高产的原因之一。

关键词: 夏玉米; 种植密度; 茎秆维管束; 茎流

\section{Effect of Plant Density on Microstructure of Stalk Vascular Bundle of Summer Maize (Zea mays L.) and Its Characteristics of Sap Flow}

\author{
FENG Hai-Juan ${ }^{1}$, ZHANG Shan-Ping ${ }^{1}$, MA Cun-Jin ${ }^{1}$, LIU Peng ${ }^{1, *}$, DONG Shu-Ting ${ }^{1}$, ZHAO Bin ${ }^{1}$, ZHANG \\ Ji-Wang ${ }^{1}$, and YANG Jin-Sheng ${ }^{2}$ \\ ${ }^{1}$ State Key Laboratory of Crop Biology / College of Agronomy, Shandong Agricultural University, Tai'an 271018, China; ${ }^{2}$ Shandong Denghai \\ Seed-Breeding Co. Ltd., Laizhou 261448, China
}

\begin{abstract}
Improving plant density is an important measure to get high yield of summer maize. Two varieties of summer maize with different density tolerances, Zhengdan 958 and Nongda 108, were used to study the effect of plant density on structure of vascular bundles of the third internode and its characteristics of sap flow under three plant densities. The results showed that the cross sectional area of stem and the amount and area of big, small vascular bundles in stalks decreased significantly with the increase of plant density, which resulted in the total number and area of vascular bundle decreased. Nongda 108 was more sensitive to plant density than Zhengdan 958. The sap flow rate and amount of sap during 8:00-17:00 decreased significantly with the increase of plant density, while the transport efficiency of stalk vascular bundle increased. There was a positive correlation between area of big vascular bundles and amount of sap flow during 8:00-17:00. The structure and function of stalk vascular bundles in Zhengdan 958 were superior to these in Nongda 108, it might be one of the reason that Zhengdan 958 with better density tolerance could get high yield.
\end{abstract}

Keywords: Summer maize; Plant density; Stalk vascular bundle; Sap flow

增加种植密度、提高光温资源利用率、依靠群 体发挥增产潜力是获得高产的重要措施之一 ${ }^{[1-3]}$ 。随
种植密度的增加, 玉米源、库性状及其生理特性都 会改变, 前人就增加密度后源库性能的变化开展了

\footnotetext{
本研究由国家自然科学基金项目(31371576, 31071358)，欧盟 FP7 国际合作项目(NUE-CROPS 222645)，国家“十二五”科技支撑计划项 目(2011BAD16B14，2012BAD04B05-2)，国家公益性行业(农业)科研专项(HY20121203100，HY1203096)，山东省财政支持农业重大应 用技术创新课题 $(2011,2013)$, 山东省良种工程玉米课题(2013)和山东省玉米育种与栽培技术企业重点实验室开放课题(2011)资助。

“通讯作者(Corresponding author): 刘鹏, E-mail: liupengsdau@126.com, Tel: 0538-8245838

第一作者联系方式: E-mail: fenghaijuan333@126.com

Received(收稿日期): 2013-12-23; Accepted(接受日期): 2014-04-16; Published online(网络出版日期): 2014-06-03.

URL: http://www.cnki.net/kcms/detail/11.1809.S.20140603.1553.011.html
} 
较多研究。李春奇等 ${ }^{[4]}$ 指出随种植密度增大, 玉米穗 位叶片厚度、叶脉横截面积和叶脉木质部面积, 上、 下表皮的气孔频度，叶肉细胞叶绿体基粒数均减小; 王晓燕等 ${ }^{[5]}$ 研究表明种植密度对各粒位籽粒灌浆影 响显著, 以穗上位籽粒受密度影响最大; 王庆成等 ${ }^{[6]}$ 发现通过改变玉米种植密度, 可以调节玉米籽粒种 皮形态建成及胚乳淀粉粒的发育速度。作物产量是 群体效应, 源库流系统协调统一是作物高产、稳产 的重要基础。近年来随着作物源库性状的改善和栽 培水平的提高, “流”的作用日益受到重视 ${ }^{[7]}$, 其研究 主要集中在维管束方面 ${ }^{[8]}$ 。水稻和小麦上, 茎(穗茎、 枝梗)维管束数目和面积与穗部性状呈显著正相关, 栽培条件影响维管束的发育 ${ }^{[9-10]}$ 。玉米上, 茎秆维管 束是“流”的重要组成部分, 负责根与冠之间的物质 交流与运输。目前关于玉米茎秆支撑功能的研究较 多。刘仲发等 ${ }^{[11]}$ 研究表明遮阴处理后, 基部茎节缩 短、直径变小, 茎秆穿刺强度降低, 且随遮阴程度增 加, 各品种倒伏率增加; 崔海岩等 ${ }^{[12]}$ 指出遮阴使玉 米茎秆硬皮组织变薄、维管束数目和单个中央大维 管束面积减小, 导致茎秆抗倒能力下降, 倒伏率增 加; 李宁等 ${ }^{[13]}$ 发现化学调节剂能降低植株高度、穗 位下部节间长度、穗高系数, 显著增加节间直径、 茎粗系数、单位茎长干物重、粗纤维含量、气生根 和总根数; 陈尚洪等 ${ }^{[14]}$ 研究表明, 密度是影响玉米 生长、产量和倒伏的主要因素, 合理施用氮肥是提 高玉米产量, 增强抗倒伏性能的重要措施。前人分
别在不同光照条件和不同栽培条件下(密度、施肥、 化学调控)研究了茎秆性状与植株抗倒伏能力的关 系，但关于经秆运输功能的研究却鲜见报道。

以热平衡为原理的包裹式茎流探头在研究直径 较小的植物茎秆液流时具有明显优越性，经 Sakuratani ${ }^{[15]}$ 、Baker 等 ${ }^{[16]}$ 和 Steinberg 等 ${ }^{[17]}$ 的发展与 完善, 实验证明其准确性较高。本文采用不同耐密 型品种、设置不同种植密度, 研究茎秆维管束结构 和功能特性对茎流速率的影响, 及茎秆维管束结构 和茎流特性对密度调控的响应，以期为玉米合理密 植提供理论依据。

\section{1 材料与方法}

\section{1 试验设计}

试验于 2012-2013 年在山东农业大学黄淮海区 域玉米技术创新中心 $\left(36^{\circ} 10^{\prime} 19^{\prime \prime} \mathrm{N}, 117^{\circ} 09^{\prime} 03^{\prime \prime} \mathrm{E}\right)$ 进 行。选用黄淮海区域广泛种植且耐密性较好的玉米 品种郑单 958 和耐密性次之的农大 108 , 设置 3 个种 植密度, 分别为 45000 株 $\mathrm{hm}^{-2}$ (低密度)、67500 株 $\mathrm{hm}^{-2}$ (中密度)和 90000 株 $\mathrm{hm}^{-2}$ (高密度), 等行距种 植, 行距 $60 \mathrm{~cm}$ 。采用裂区设计, 密度为主区, 品种 为裂区, 4 次重复, 小区长 $15 \mathrm{~m}$, 宽 $6 \mathrm{~m}$, 面积为 $90 \mathrm{~m}^{2}$ 。2 2012 年 6 月 14 日人工点播, 10 月 2 日收获; 2013 年 6 月 15 日人工点播, 10 月 5 日收获。玉米生 育期间的天气状况见表 1 , 生育期内水分和养分供 应充足，无病虫草害。

表 1 玉米生长期间的天气状况

Table 1 Weather conditions in the process of maize growth

\begin{tabular}{|c|c|c|c|c|}
\hline $\begin{array}{l}\text { 年度 } \\
\text { Year }\end{array}$ & $\begin{array}{c}\text { 有效积温 } \\
\text { Effective accumulative temperature } \\
\left(\geq 10^{\circ} \mathrm{C}\right)\end{array}$ & $\begin{array}{c}\text { 降雨量 } \\
\text { Total precipitation } \\
(\mathrm{mm})\end{array}$ & $\begin{array}{c}\text { 日均气温 } \\
\text { Average daily air temperature } \\
\left({ }^{\circ} \mathrm{C}\right)\end{array}$ & $\begin{array}{c}\text { 日照时数 } \\
\text { Sunshine hours } \\
\text { (h) }\end{array}$ \\
\hline 2012 & 1681.8 & 356.7 & 25.2 & 605.7 \\
\hline 2013 & 1765.7 & 401.6 & 25.6 & 732.2 \\
\hline
\end{tabular}

试验田 0 20 cm 耕层土壤含有机质 $10.55 \mathrm{~g} \mathrm{~kg}^{-1}$ 、 全氮 $0.79 \mathrm{~g} \mathrm{~kg}^{-1}$ 、碱解氮 $57.59 \mathrm{mg} \mathrm{kg}^{-1}$ 、速效磷 37.25 $\mathrm{mg} \mathrm{kg}^{-1}$ 、速效钾 $126.72 \mathrm{mg} \mathrm{kg}^{-1}$ 。

\section{2 测定项目与方法}

\subsection{1 茎秆显微结构在灌浆期 18:00 左右截取} 各处理植株地上第 3 茎节, 测量其横截面积后以徒 手切片, 番红染色, 于 DM21-J1200 型显微镜下观 察计数并拍照, 用 MIAS-1 型显微图像分析软件分 析维管束结构, 包括大、小维管束 $(\mathrm{Vb})$ 的数目及面 积等。
1.2.2 茎流速率 采用美国 Dynamax 公司开发 的 SGB-25M 型包裹式茎流计测定茎流速率(SF)。限 于探头数目, 仅在中密度与低密度试验区, 选取具 有代表性的玉米植株, 将茎流传感器包裹在玉米的 地上第 3 节茎秆上, 与数据自动采集器 DateTaker 80 相连接, 每 $30 \mathrm{~min}$ 自动测定并记录一次茎秆内的液 流速率，每 $6 \mathrm{~d}$ 左右将其拆卸以散发其聚集的热量 并检查玉米茎秆有无损坏 ${ }^{[18]}$ 。

1.2.3 茎流总量及维管束运输效率计算 8:00 至

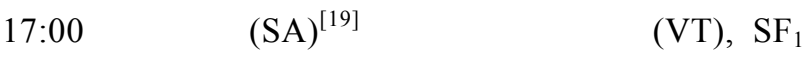


表示 8:00 的茎流速率, $\mathrm{SF}_{2}$ 表示 $8: 30$ 的茎流速率, 依 次类推。

$$
\begin{aligned}
& S A=\sum\left(\frac{S F_{n+1}+S F_{n}}{2} \times 0.5 \mathrm{~h}\right),(n \text { 为 } 1,2,3, \ldots, 19) \\
& V T=\frac{S A}{9 \mathrm{~h} \times S_{01}},
\end{aligned}
$$

式中, $S_{01}$ 为大维管束总面积。

1.2.4 数据处理与分析 采用 SigmaPlot 10.0 和 DPS 数据处理系统分析数据, 采用 LSD 法(最小显著 差异法)进行多重比较。2年数据趋势一致, 主要使用 2013年数据。

\section{2 结果与分析}

2.1 茎秆显微结构的变化

2.1.1 维管束数目 茎秆中的维管束为外韧维管 束, 可分为两类, 一类是茎秆边缘的 2 3 层维管束, 排列紧密, 绝大部分发育不完全, 只有木质部, 单 个维管束面积较小, 维管束周圈围绕有几层厚壁组 织, 低密度下的维管束较中、高密度下排列更为均 匀整齐, 称为小维管束(图 1); 另一类是松散分布于 茎秆中央的维管束, 结构发育完整, 单个维管束面 积较大, 称为大维管束(图 2)。由表 2 可以看出, 两 品种在大维管束数目 $\left(\mathrm{N}_{1}\right)$ 、小维管束数目 $\left(\mathrm{N}_{2}\right)$ 、总维
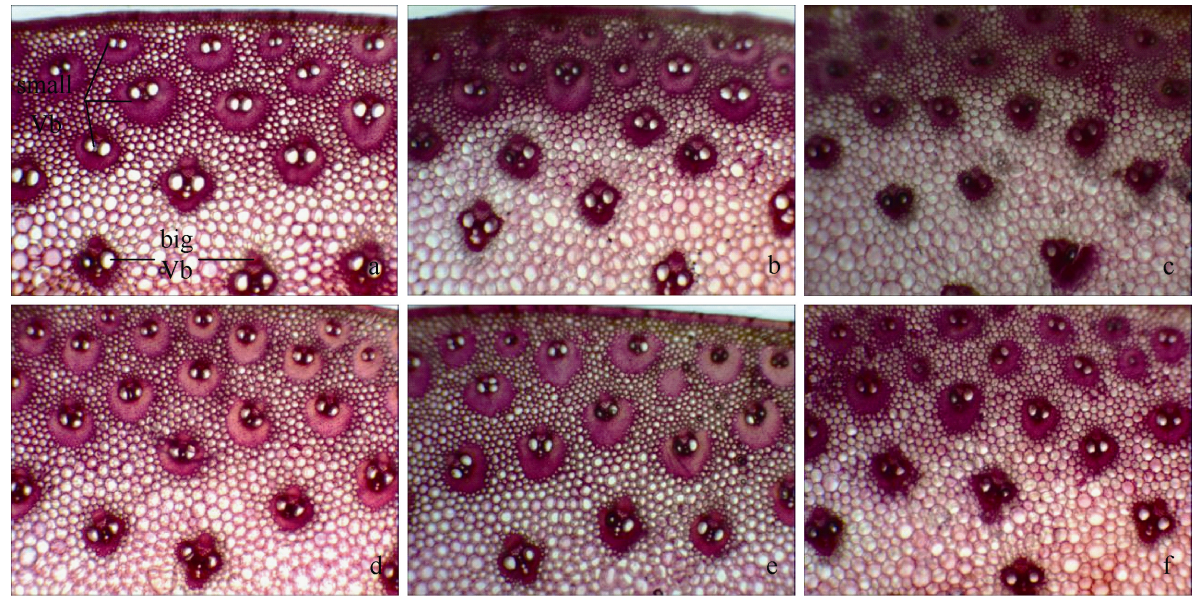

图 1 灌浆期不同密度下的第 3 节茎秆的边缘维管束

Fig. 1 The edge $\mathrm{Vb}$ of the third internode at filling stage of different varieties in different planting densities

a: 农大 108, 4.5 万株 $\mathrm{hm}^{-2}(\times 40) ;$ b: 农大 108, 6.75 万株 $\mathrm{hm}^{-2}(\times 40) ; \mathrm{c}$ ：农大 $108,9.00$ 万株 $\mathrm{hm}^{-2}(\times 40)$; d: 郑单 $958,4.5$ 万株 $\mathrm{hm}^{-2}(\times 40)$; e: 郑单 $958,6.75$ 万株 $\mathrm{hm}^{-2}(\times 40)$; f: 郑单 $958,9.00$ 万株 $\mathrm{hm}^{-2}(\times 40)$ 。

a: Nongda $108,4.5 \times 10^{4}$ plant $\mathrm{hm}^{-2}(\times 40)$; b: Nongda $108,6.75 \times 10^{4} \mathrm{hm}^{-2}(\times 40)$; c: Nongda $108,9.00 \times 10^{4} \mathrm{hm}^{-2}(\times 40)$; d: Zhengdan 958 , $4.5 \times 10^{4}$ plant $\mathrm{hm}^{-2}(\times 40)$; e: Zhengdan 958, $6.75 \times 10^{4}$ plant $\mathrm{hm}^{-2}(\times 40)$; f: Zhengdan 958, 9.00×10 ${ }^{4} \mathrm{plant} \mathrm{hm}^{-2}(\times 40)$.
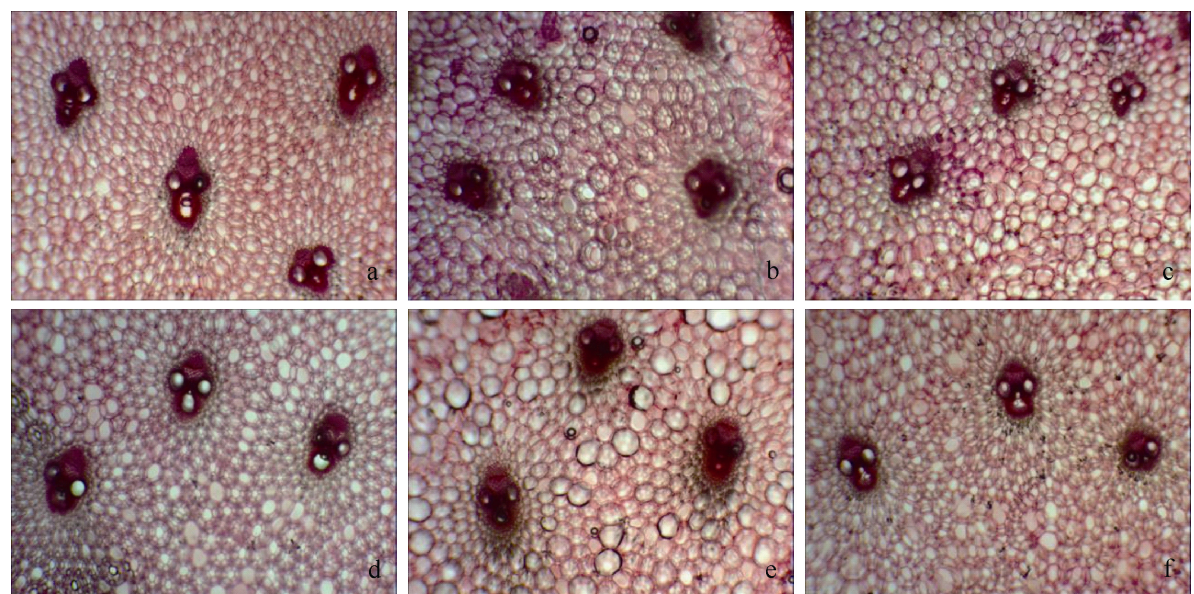

图 2 灌浆期不同密度下的第 3 节茎秆的中央维管束

Fig. 2 The center Vb of the third internode at filling stage in different planting densities

a: 农大 $108,4.5$ 万株 $\mathrm{hm}^{-2}(\times 40)$; b: 农大 $108,6.75$ 万株 $\mathrm{hm}^{-2}(\times 40)$; c: 农大 $108,9.00$ 万株 $\mathrm{hm}^{-2}(\times 40)$; d: 郑单 $958,4.5$ 万株 $\mathrm{hm}^{-2}(\times 40)$;

e: 郑单 $958,6.75$ 万株 $\mathrm{hm}^{-2}(\times 40)$; f: 郑单 $958,9.00$ 万株 $\mathrm{hm}^{-2}(\times 40)$ 。

a: Nongda 108, $4.5 \times 10^{4}$ plant hm ${ }^{-2}(\times 40)$; b: Nongda $108,6.75 \times 10^{4} \mathrm{hm}^{-2}(\times 40)$; c: Nongda 108, 9.00 $\times 10^{4} \mathrm{hm}^{-2}(\times 40)$; d: Zhengdan 958 , $4.5 \times 10^{4}$ plant $\mathrm{hm}^{-2}(\times 40)$; e: Zhengdan $958,6.75 \times 10^{4}$ plant hm $\mathrm{hm}^{-2}(\times 40)$; f: Zhengdan $958,9.00 \times 10^{4} \mathrm{plant} \mathrm{hm}^{-2}(\times 40)$. 
表 2 种植密度对第 3 茎节维管束数目的影响

Table 2 Effects of plant density on number of vascular bundles of the third internode

\begin{tabular}{|c|c|c|c|c|c|c|}
\hline $\begin{array}{l}\text { 年份 } \\
\text { Year }\end{array}$ & $\begin{array}{c}\text { 品种 } \\
\text { Cultivar }\end{array}$ & $\begin{array}{c}\text { 密度 } \\
\text { Plant density } \\
\left(\text { plant } \mathrm{hm}^{-2} \text { ) }\right.\end{array}$ & $\begin{array}{c}\text { 大维管束数目 } \\
\text { Number of big } \\
\text { Vb }\end{array}$ & $\begin{array}{c}\text { 小维管束数目 } \\
\text { Number of } \\
\text { small Vb }\end{array}$ & $\begin{array}{c}\text { 维管束总数目 } \\
\text { Number of total } \\
\text { Vb }\end{array}$ & $\begin{array}{c}\text { 第 } 3 \text { 茎节横截面积 } \\
\text { Transection area of the } \\
\text { third internode }\left(\mathrm{mm}^{2}\right)\end{array}$ \\
\hline \multirow[t]{6}{*}{2012} & 农大 108 & 45000 & $260.8 \mathrm{a}$ & $411.3 \mathrm{a}$ & $672.1 \mathrm{a}$ & $493.5 \mathrm{a}$ \\
\hline & Nongda 108 & 67500 & $249.5 \mathrm{~b}$ & $369.5 \mathrm{~b}$ & $619.0 \mathrm{~b}$ & $393.7 \mathrm{~b}$ \\
\hline & & 90000 & $222.5 \mathrm{c}$ & $345.5 \mathrm{~b}$ & $568.0 \mathrm{c}$ & $351.4 \mathrm{c}$ \\
\hline & 郑单 958 & 45000 & $312.0 \mathrm{a}$ & $453.2 \mathrm{a}$ & $765.2 \mathrm{a}$ & $459.6 \mathrm{a}$ \\
\hline & Zhengdan 958 & 67500 & $268.6 \mathrm{~b}$ & $391.5 \mathrm{~b}$ & $660.1 \mathrm{~b}$ & $446.4 \mathrm{a}$ \\
\hline & & 90000 & $251.8 \mathrm{c}$ & $326.0 \mathrm{c}$ & $577.8 \mathrm{c}$ & $363.3 \mathrm{~b}$ \\
\hline \multirow[t]{6}{*}{2013} & 农大 108 & 45000 & $233.6 \mathrm{a}$ & $413.5 \mathrm{a}$ & $647.1 \mathrm{a}$ & $470.8 \mathrm{a}$ \\
\hline & Nongda 108 & 67500 & $221.6 \mathrm{~b}$ & $371.9 \mathrm{~b}$ & $593.5 \mathrm{~b}$ & $366.6 \mathrm{~b}$ \\
\hline & & 90000 & $208.8 \mathrm{c}$ & $351.1 \mathrm{~b}$ & $559.9 \mathrm{c}$ & $340.2 \mathrm{c}$ \\
\hline & 郑单 958 & 45000 & $298.8 \mathrm{a}$ & $438.1 \mathrm{a}$ & $736.9 \mathrm{a}$ & $426.6 \mathrm{a}$ \\
\hline & Zhengdan 958 & 67500 & $246.8 \mathrm{~b}$ & $408.3 \mathrm{~b}$ & $655.2 \mathrm{~b}$ & $418.6 \mathrm{a}$ \\
\hline & & 90000 & $236.2 \mathrm{c}$ & $344.7 \mathrm{c}$ & $568.6 \mathrm{c}$ & $349.9 \mathrm{~b}$ \\
\hline
\end{tabular}

同列中标以不同小写字母的数值在 0.05 水平上差异显著。

Values within a column followed by a different letter are significantly different at 0.05 probability level.

管束数目 $\left(\mathrm{N}_{0}\right)$ 及维管束总横截面积上存在显著差异, 表现为郑单 958>农大 108 。同一品种不同密度处理 间的大维管束数目差异均达显著水平, 表现为随密 度升高而降低。两年数据趋势一致。

\subsection{2 维管束面积 从表 3 可以看出, 种植密度} 对茎秆维管束面积的发育影响显著。随密度增加, 大维管束的平均面积、小维管束平均面积和维管束 总面积均呈减小趋势, 不同品种对密度的反应有差 异(图1和图2)。2个品种的大维管束平均面积、大维
管束总面积和维管束总面积密度处理间差异均达显 著水平, 只有小维管束平均面积在中、高密度下差 异不显著。维管束总面积占茎秆总横截面积的比例, 农大 108 高密度与中、低密度间差异显著，而中、低 密度间无显著差异; 郑单958则表现为低密度与中、 高密度差异显著, 中、高密度间差异不显著, 说明农 大108对密度增加更为敏感。

由 2012 年数据可知, 农大 108 和郑单 958 的大维 管束平均面积, 均在 90000 株 $\mathrm{hm}^{-2}$ 密度下最小, 分别

表 3 种植密度对第 3 茎节维管束面积的影响

Table 3 Effects of plant density on area of vascular bundles of the third internode

\begin{tabular}{|c|c|c|c|c|c|c|c|c|c|}
\hline $\begin{array}{l}\text { 年份 } \\
\text { Year }\end{array}$ & $\begin{array}{c}\text { 品种 } \\
\text { Cultivar }\end{array}$ & $\begin{array}{c}\text { 密度 Plant density } \\
\left(\text { plant } \mathrm{hm}^{-2}\right)\end{array}$ & $\begin{array}{c}\mathrm{S}_{1} \\
\left(\mathrm{~mm}^{2}\right)\end{array}$ & $\begin{array}{c}\mathrm{S}_{2} \\
\left(\mathrm{~mm}^{2}\right)\end{array}$ & $\begin{array}{c}\mathrm{S}_{01} \\
\left(\mathrm{~mm}^{2}\right)\end{array}$ & $\begin{array}{c}\mathrm{S}_{02} \\
\left(\mathrm{~mm}^{2}\right)\end{array}$ & $\begin{array}{l}\mathrm{S}_{\text {total }} \\
\left(\mathrm{mm}^{2}\right)\end{array}$ & $\begin{array}{c}\mathrm{S}_{0} \\
\left(\mathrm{~mm}^{2}\right)\end{array}$ & $\begin{array}{c}\mathrm{S}_{\text {total }} / \mathrm{S}_{0} \\
(\%)\end{array}$ \\
\hline \multirow[t]{6}{*}{2012} & 农大 108 & 45000 & $0.112 \mathrm{a}$ & $0.035 \mathrm{a}$ & $29.21 \mathrm{a}$ & $14.40 \mathrm{a}$ & $43.61 \mathrm{a}$ & $493.52 \mathrm{a}$ & $8.84 \mathrm{a}$ \\
\hline & Nongda 108 & 67500 & $0.094 \mathrm{~b}$ & $0.028 \mathrm{~b}$ & $23.57 \mathrm{~b}$ & $10.34 \mathrm{~b}$ & $33.91 \mathrm{~b}$ & $393.68 \mathrm{a}$ & $8.61 \mathrm{a}$ \\
\hline & & 90000 & $0.081 \mathrm{~b}$ & $0.025 \mathrm{~b}$ & $17.96 \mathrm{c}$ & $8.63 \mathrm{c}$ & $26.58 \mathrm{c}$ & $351.44 \mathrm{~b}$ & $7.56 \mathrm{~b}$ \\
\hline & 郑单 958 & 45000 & $0.097 \mathrm{a}$ & $0.031 \mathrm{a}$ & $26.05 \mathrm{a}$ & $11.35 \mathrm{a}$ & $44.31 \mathrm{a}$ & $459.59 \mathrm{a}$ & $9.64 \mathrm{a}$ \\
\hline & Zhengdan 958 & 67500 & $0.091 \mathrm{ab}$ & $0.022 \mathrm{~b}$ & $24.31 \mathrm{~b}$ & $8.70 \mathrm{~b}$ & $33.01 \mathrm{~b}$ & $426.45 \mathrm{a}$ & $7.74 \mathrm{~b}$ \\
\hline & & 90000 & $0.083 \mathrm{~b}$ & $0.020 \mathrm{~b}$ & $20.93 \mathrm{c}$ & $6.59 \mathrm{c}$ & $27.52 \mathrm{c}$ & $363.31 \mathrm{~b}$ & $7.57 \mathrm{~b}$ \\
\hline \multirow[t]{6}{*}{2013} & 农大 108 & 45000 & $0.106 \mathrm{a}$ & $0.031 \mathrm{a}$ & $24.66 \mathrm{a}$ & $12.87 \mathrm{a}$ & $37.31 \mathrm{a}$ & $470.80 \mathrm{a}$ & $7.93 \mathrm{a}$ \\
\hline & Nongda 108 & 67500 & $0.085 \mathrm{~b}$ & $0.025 \mathrm{~b}$ & $18.88 \mathrm{~b}$ & $9.20 \mathrm{~b}$ & $28.09 \mathrm{~b}$ & $366.65 \mathrm{~b}$ & $7.67 \mathrm{ab}$ \\
\hline & & 90000 & $0.073 \mathrm{~b}$ & $0.024 \mathrm{~b}$ & $15.16 \mathrm{c}$ & $8.28 \mathrm{c}$ & $24.07 \mathrm{c}$ & $340.24 \mathrm{c}$ & $7.08 \mathrm{~b}$ \\
\hline & 郑单 958 & 45000 & $0.093 \mathrm{a}$ & $0.027 \mathrm{a}$ & $27.70 \mathrm{a}$ & $11.85 \mathrm{a}$ & $39.57 \mathrm{a}$ & $426.62 \mathrm{a}$ & $9.27 \mathrm{a}$ \\
\hline & Zhengdan 958 & 67500 & $0.086 \mathrm{ab}$ & $0.022 \mathrm{~b}$ & $21.16 \mathrm{~b}$ & $9.04 \mathrm{~b}$ & $29.53 \mathrm{~b}$ & $418.61 \mathrm{a}$ & $7.05 \mathrm{~b}$ \\
\hline & & 90000 & $0.075 \mathrm{~b}$ & $0.021 \mathrm{~b}$ & $17.72 \mathrm{c}$ & $7.48 \mathrm{c}$ & $24.25 \mathrm{c}$ & $349.91 \mathrm{~b}$ & $6.93 \mathrm{~b}$ \\
\hline
\end{tabular}

$\mathrm{S}_{1}$ ：单个大维管束平均面积; $\mathrm{S}_{2}$ ：单个小维管束平均面积; $\mathrm{S}_{01}$ ：大维管束总面积; $\mathrm{S}_{02}$ ：小维管束总面积; $\mathrm{S}_{\text {total }}$ ：维管束总面积; $\mathrm{S}_{0}$ ： 第 3 茎节横截面积; $\mathrm{S}_{\mathrm{total}} / \mathrm{S}_{0}$ : 维管束总面积占茎秆横截面积的百分比。同列中标以不同小写字母的数值在 0.05 水平上差异显著。

$\mathrm{S}_{1}$ : average area of single big $\mathrm{Vb} ; \mathrm{S}_{2}$ : average area of single small $\mathrm{Vb} ; \mathrm{S}_{01}$ : total area of big $\mathrm{Vb} ; \mathrm{S}_{02}$ : total area of small $\mathrm{Vb} ; \mathrm{S}_{\mathrm{total}}$ : total area of $\mathrm{Vb} ; \mathrm{S}_{0}$ : transection area of the third internode; $\mathrm{S}_{\text {total }} / \mathrm{S}_{0}$ : the percentage of the total area of vascular bundle to stem cross-sectional area. Values within a column followed by a different letter are significantly different at 0.05 probability level 
为 $0.081 \mathrm{~mm}^{2}$ 和 $0.083 \mathrm{~mm}^{2}$, 高密度比中密度分别减少 $13.83 \%$ 和 $8.79 \%$, 比低密度减少 $27.68 \%$ 和 $14.43 \%$; 农 大 108 和郑单 958 的维管束总面积在 90000 株 $\mathrm{hm}^{-2}$ 密 度下分别为 $26.58 \mathrm{~mm}^{2}$ 和 $27.52 \mathrm{~mm}^{2}$, 高密度比中密度 分别减少 $21.62 \%$ 和 $16.63 \%$, 比低密度分别减少 $39.05 \%$ 和 $37.89 \%$ 。说明种植密度的增加对维管束总面积的影 响要大于对大维管束平均面积的影响。2个指标均表明 郑单958受密度影响小于农大 108 。

由 2013 年数据可知, 农大 108 和郑单 958 在大 维管束平均面积上, 高密度比中密度分别减少 $14.79 \%$ 和 $12.49 \%$, 比低密度分别减少 $31.25 \%$ 和 19.09\%; 高密度下农大 108 和郑单 958 维管束总面 积比中密度分别减小 $17.27 \%$ 和 $16.54 \%$, 比低密度分 别减小 $36.94 \%$ 和 $35.64 \%$ 。随密度增加，郑单 958 减小 的幅度小于农大 108 , 说明郑单 958 相对农大 108 在维 管束面积上受密度的影响较小, 与 2012 年趋势一致。

\section{2 茎流速率的变化规律}

晴天条件下空气温度随太阳辐射能的增加而增 加, 随太阳辐射能的减小而减小, 太阳落山后空气 温度持续下降, 温度与太阳辐射之间存在一定时滞 效应(图 3)。

相同环境条件下, 不同密度的植株 SF 变化规律 基本一致, 呈单峰曲线变化, 8:00 左右开始上升, 11:30 至 13:30 出现峰值, 之后逐渐下降, 大约在 19:00 至 20:00 降至最低值, 并在随后维持较低水平。 各处理 SF 日变化曲线和各日峰形变化与同步检测 的太阳辐射强度、温度的变化趋势基本相同(图 3 和 图 4)。太阳辐射强度既能诱导气孔启闭, 又决定空气 温度、相对湿度和叶片温度的变化, 是影响灌木液 流变化的最主要因子, 液流启动和峰值出现的时间 与光照紧密相关 ${ }^{[20]}$ 。不同密度下的植株 $\mathrm{SF}$ 差别主要 出现在 8:00 至 17:00 之间, 表现为随密度增加呈

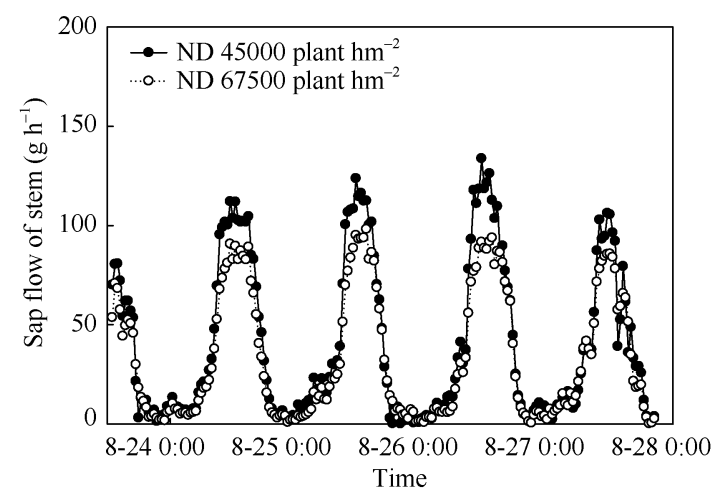

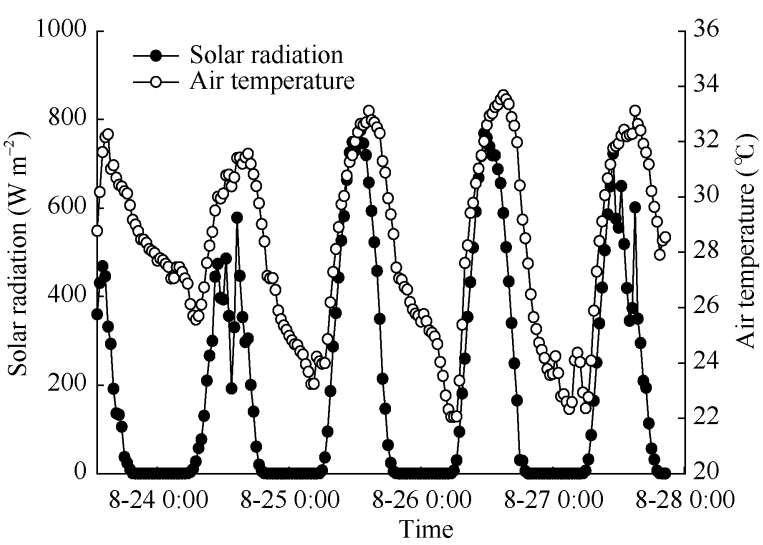

图 3 太阳辐射与空气温度变化 (8 月 23 日至 27 日)

Fig. 3 Variation of solar radiation and air temperature (Aug. 23-27)

降低趋势, 9:00 至 16:00 尤为明显。两品种不同密度 条件下的 SF 有显著差异, 且郑单 958>农大 108 。

对 8 月 26 日的 SF 及 SA 比较可知(图 5), 同等 密度条件下 $\mathrm{SF}$ 与 $\mathrm{SA}$ 均表现为郑单 958>农大 108 。 农大 108 在低密度下的最高 $\mathrm{SF}$ 为 $133.73 \mathrm{~g} \mathrm{~h}^{-1}$, 中密 度下为 $93.73 \mathrm{~g} \mathrm{~h}^{-1}$, 中密度比低密度降低 $29.91 \%$; 农大 108 的 SA, 低密度下是 $901.74 \mathrm{~g}$, 中密度下是 $713.49 \mathrm{~g}$, 中密度比低密度减小 $20.88 \%$ 。而郑单 958 在低密度下的峰值为 $169.00 \mathrm{~g} \mathrm{~h}^{-1}$, 中密度下的峰值 为 $161.03 \mathrm{~g} \mathrm{~h}^{-1}$, 中密度比低密度只降低 $4.72 \%$; 郑 单 958 的 SA, 低密度下是 $1031.85 \mathrm{~g}$, 中密度下是 $868.56 \mathrm{~g}$, 中密度比低密度降低 $15.82 \%$ 。说明农大 108 的 SF、SA 受密度的影响大于郑单 958 。

\section{3 茎流效率的变化}

郑单 958 的 $\mathrm{VT}$ 在低密度下是 $2.91 \mathrm{~g} \mathrm{~h}^{-1} \mathrm{~mm}^{-2}$, 中密度下是 $3.21 \mathrm{~g} \mathrm{~h}^{-1} \mathrm{~mm}^{-2}$, 密度增加后, 其 VT 增 加 $10.31 \%$; 农大 108 在低密度下是 $2.79 \mathrm{~g} \mathrm{~h}^{-1} \mathrm{~mm}^{-2}$, 中密度下是 $2.86 \mathrm{~g} \mathrm{~h}^{-1} \mathrm{~mm}^{-2}$, 密度增加后, 其 VT仅增 加 $2.51 \%$ 。随密度增加, 单株茎秆维管束面积变小,

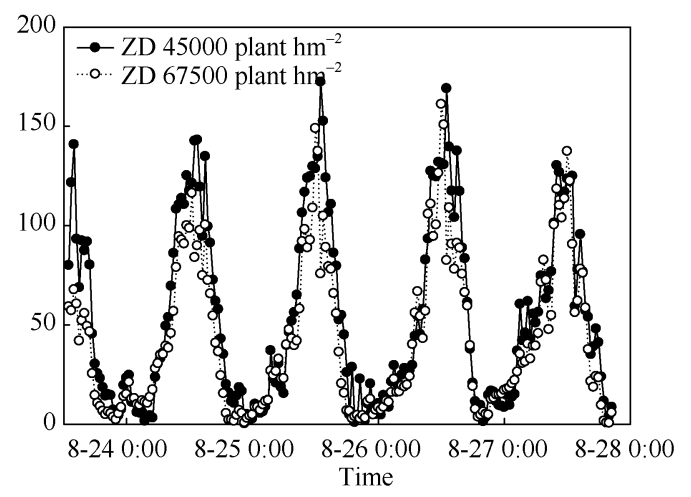

图 4 种植密度对不同品种茎流速率的影响(8 月 23 日至 27 日)

Fig. 4 Effects of planting density on stem sap flow in different maize varieties (Aug. 23-27) 
但 VT 增加，郑单 958 的增加幅度远大于农大 108 。 2.4 茎秆基部维管束结构参数与茎流的相关分析 相关分析表明(表4), SA 与大维管束总面积呈 显著正相关, 说明植株在较高密度下通过提高维管

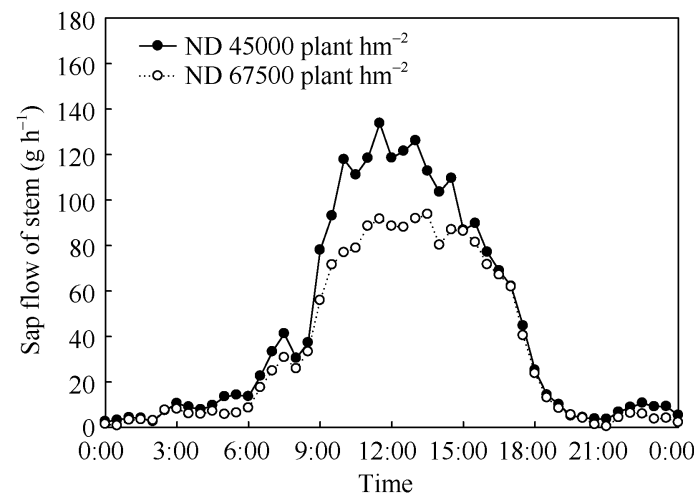

束的运输效率来满足植株本身代谢所需, 以对抗密 度增加所造成的个体之间竞争的激化。郑单958的 维管束运输效率高于农大 108 , 表现出一定的品种 优势。

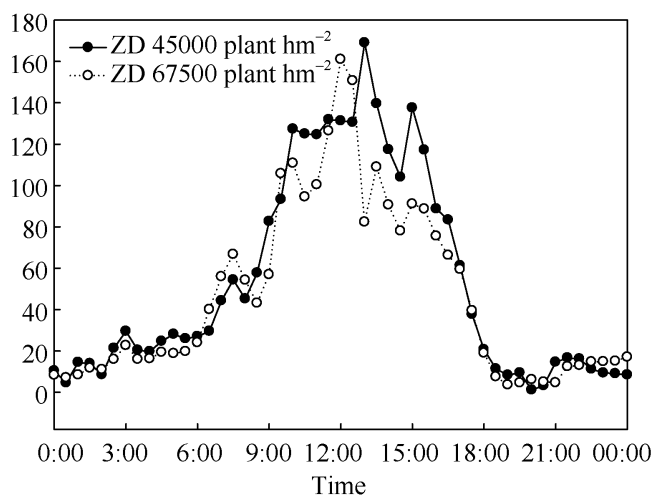

图 5 不同品种茎流速率的日变化 $(8$ 月 26 日，晴 $)$

Fig. 5 The diurnal variation of sap flow rate of different cultivars (Aug. 26, sunny)

表 4 玉米 8:00 至 17:00 总茎流量、运输效率与维管束数目、面积的相关性分析

Table 4 Correlation coefficients of diurnal water consumption and transport efficiency with amount and area of vascular bundle

\begin{tabular}{lccccc}
\hline & $\mathrm{S}_{01}\left(\mathrm{~mm}^{2}\right)$ & $\mathrm{S}_{02}\left(\mathrm{~mm}^{2}\right)$ & $\mathrm{S}_{\text {total }}\left(\mathrm{mm}^{2}\right)$ & $\mathrm{N}_{1}$ & $\mathrm{~N}_{2}$ \\
\hline 8:00 至 17:00 的总茎流量 SA & $0.957^{*}$ & 0.819 & 0.928 & 0.886 & 0.798 \\
8:00 至 17:00 的维管束运输效率 VT & -0.259 & -0.539 & -0.342 & 0.127 & 0.393 \\
\hline
\end{tabular}

$\mathrm{S}_{01}$ ：大维管束总面积; $\mathrm{S}_{02}$ ：小维管束总面积; $\mathrm{S}_{\text {total }}$ ：维管束总面积; $\mathrm{N}_{1}$ ：大维管束数目; $\mathrm{N}_{2}$ ：小维管束数目; $\mathrm{N}_{0}$ ：维管束总数目。 *表示在 0.05 水平显著相关。

$\mathrm{S}_{01}$ : total area of big $\mathrm{Vb} ; \mathrm{S}_{02}$ : total area of small $\mathrm{Vb} ; \mathrm{S}_{\text {total }}$ : total area of $\mathrm{Vb} ; \mathrm{N}_{1}$ : number of big $\mathrm{Vb}$; $\mathrm{N}_{2}$ : number of small $\mathrm{Vb}$; $\mathrm{N}_{0}$ : number of total $\mathrm{Vb}$; SA: the amount of sap flow from 8:00 to 17:00; VT: the transport efficiency of vascular bundle from 8:00 to 17:00. ${ }^{*}$ stands for significance at 0.05 probability level.

\section{3 讨论}

\section{1 种植密度对茎秆维管束显微结构的影响} 在作物产量形成过程中, 根和叶属于源的范畴, 茎主要具运输营养物质的功能 ${ }^{[21]}$, 是水分及无机盐 等营养物质向地上部输送的通道, 因此作物茎秆维 管束的结构显著影响产量 ${ }^{[10,22-23]}$ 。适当提高种植密 度能增加玉米杼粒产量, 但如果种植密度过大, 玉 米个体间对养分、水分和光照的竞争激烈, 通风透 光条件差, 会使植株的茎秆变细, 高度增加, 生长 势弱 ${ }^{24]}$, 而不同耐密性玉米品种对密度增加的反应 程度不同。周宇飞等 ${ }^{[25]}$ 认为密植性玉米对密度压力 的反应要早于稀植性玉米, 其在高密度表现出的适 应性也要优于稀植性玉米。本研究发现种植密度显 著影响玉米茎秆维管束结构: 增加种植密度, 茎秆 中大、小维管束数目减小, 大维管束数目、总维管 束数目在密度处理间均有显著差异, 这与水稻、小 麦上的研究结果一致 ${ }^{[9,26]}$; 大、小维管束平均面积减 小, 总维管束面积减小, 农大 108 在这 2 个指标上的
降低幅度均大于郑单 958 。农大 108 维管束总面积占 茎秆总横截面积的比例, 高密度与中、低密度间差 异显著, 中、低密度间无显著差异; 而郑单958表现 为低密度与中、高密度差异显著, 中、高密度间差 异不显著, 说明不同品种对密度增加的敏感度不同, 郑单 958 较农大 108 更耐密, 表现出在维管束结构上 的优势。因此在育种工作中, 应该注重选择茎秆维 管束相对面积较高的材料, 以便从中选出产量潜力 高的品种。

\section{2 种植密度对茎流特性的影响}

近年来, 已有研究证明作物的“流”器官的重要生 理指标—茎流速率可以充分反映叶片中合成的光合 产物运输速度及叶片水分的亏缺程度 ${ }^{[27]}$ 。李国臣等 ${ }^{[28]}$ 研究指出在相同的气象条件下, 基于时间过程的充 分供水与水分亏缺条件下的茎流变化曲线间的相关 系数的大小可以反映作物的水分亏缺。刘永红等 ${ }^{[29]}$ 指出在干旱胁迫条件下, 植物生长调节剂能显著抑 制植株茎流强度, 减少植株失水。李会等 ${ }^{[18]}$ 、赵永玲 
等 ${ }^{[30]}$ 研究表明夏玉米 SF 日变化在晴好天气下呈单峰 曲线, 早上启动, 中午达到峰值, 晚上保持在低值, 与太阳辐射、饱和水气压差、风速等变化趋势十分相 似, 主要受太阳辐射的影响。本研究进一步明确了晴 天时黄淮海区域夏玉米 $\mathrm{SF}$ 的日变化规律, $\mathrm{SF}$ 呈单峰 曲线变化, 8:00 左右开始上升, 11:30 至 13:30 出现峰 值, 之后逐渐下降, 大约在 19:00 至 20:00 降至最低值, 并在随后维持较低水平; 各 $\mathrm{SF}$ 连日变化曲线和各日 峰形变化与同步检测的太阳辐射强度、温度的变化趋 势基本相同。茎流速率在中午峰值附近出现小幅波动, 这可能是大气蒸发能力过高, 茎流速率高于根系吸 水速率, 致使导管内的水柱出现空穴而时断时续, 而 夜间平稳的上升液流的存在主要归结于根压产生的 主动吸收 ${ }^{[31]}$; 此外, 本研究发现同一密度下, 农大 108 的 SF、SA 和 VT 均显著小于郑单 958; 密度处理 间, 农大 108 和郑单 958 的 SA 均表现为中密度 $<$ 低密 度，中密度比低密度分别降低 $20.88 \%$ 和 $15.82 \%$, 农 大 108 的降幅大于郑单 958, 说明农大 108 受密度影 响大于郑单 958。相关分析表明, SA 与大维管束总面 积呈显著正相关。随密度增加, 茎秆大维管束总面积 减小, SF、SA 下降, 但其 VT 增加, 郑单 958 从低密 度到中密度增加 $10.31 \%$, 农大 108 则仅增加 $2.51 \%$, 郑单 958 的增加幅度远大于农大 108 , 说明两品种对 密度的响应不同, 郑单 958 较农大 108 表现出在 SF、 $\mathrm{SA}$ 和 VT 上的优势。

\section{4 结论}

种植密度显著影响夏玉米的茎秆显微结构与茎 流速率。随密度增加, 维管束数目与横截面积下降, 茎流速率及总茎流量变小。总茎流量与大维管束总面 积呈显著正相关, 植株在较高密度下通过提高维管 束的运输效率来对抗密度增加所造成的个体之间竞 争的激化。密植后郑单 958 的维管束结构优于农大 108 , 表现出茎流速率、总茎流量及运输效率上的优势, 这 可能是其密度增大后仍能获得高产的原因之一。

\section{References}

[1] 段民孝. 从农大 108 和郑单 958 中得到的玉米育种启示. 玉米 科学, 2005, 13(4): 49-52

Duan M X. Some advice on corn breeding obtained from the elite varieties of Nongda 108 and Zhengdan 958. J Maize Sci, 2005, 13(4): 49-52 (in Chinese with English abstract)

[2] 陈传永, 侯玉虹, 孙锐, 朱平, 董志强, 赵明. 密植对不同玉 米品种产量性能的影响及其耐密性分析. 作物学报, 2010, 36: $1153-1160$
Chen C Y, Hou Y H, Sun R, Zhu P, Dong Z Q, Zhao M. Effects of planting density on yield performance and density-tolerance analysis for maize hybrids. Acta Agron Sin, 2010, 36: 1153-1160 (in Chinese with English abstract)

[3] 赵明, 李建国, 张宾, 董志强, 王美云. 论作物高产挖潜的补 偿机制. 作物学报, 2006, 32: 1566-1573

Zhao M, Li J G, Zhang B, Dong Z Q, Wang M Y. The compensatory mechanism in exploring crop production potential. Acta Agron Sin, 2006, 32: 1566-1573 (in Chinese with English abstract)

[4] 李春奇, 王庭梁, 程相文, 曹诺遥, 李芸, 芦鹏, 李潮海. 种植 密度对夏玉米穗位叶片解剖结构的影响. 作物学报, 2011, 37: 2099-2105

Li C Q, Wang T L, Cheng X W, Cao N Y, Li Y, Lu P, Li C H. Effects of plant density on anatomical structure of ear leaf in summer maize. Acta Agron Sin, 2011, 37: 2099-2105 (in Chinese with English abstract)

[5] 王晓燕, 张洪生, 盖伟玲, 段梅堂, 姜雯. 种植密度对不同玉 米品种产量及籽粒灌浆的影响. 山东农业科学, 2011，(4): $36-38$

Wang X Y, Zhang H S, Gai W L, Duan M T, Jiang W. Effects of plant density on yield and kernel filling of different maize varieties. Shandong Agric Sin, 2011, (4): 36-38 (in Chinese with English abstract)

[6] 王庆成, 刘霞, 李宗新, 刘开昌. 种植密度对玉米种皮形态建 成及胚乳淀粉粒发育的影响. 中国农业科学, 2008，41: 2506-2512

Wang Q C, Liu X, Li Z X, Liu K C. Effect of planting densities on morphogenesis of seed capsule and development of starch granule in maize endosperm. Sci Agric Sin, 2008, 41: 2506-2512 (in Chinese with English abstract)

[7] 何启平, 董树亭, 高荣岐. 不同类型玉米品种果穗维管束的比 较研究. 作物学报, 2007, 33: 1187-1196

He Q P, Dong S T, Gao R Q. Comparison of ear vascular bundles in different maize cultivars. Acta Agron Sin, 2007, 33: 1187-1196 (in Chinese with English abstract)

[8] 王娜, 李凤海, 王志斌, 王宏伟, 吕香玲, 周宇飞, 史振声. 不 同耐密型玉米品种茎秆性状对密度的响应及与倒伏的关系. 作物杂志, 2011, (3): 67-70

Wang N, Li F H, Wang Z B, Wang H W, Lü X L, Zhou Y F, Shi Z $\mathrm{S}$. Response to plant density of stem characters of maize hybrids and its relationship to lodging. Crops, 2011, (3): 67-70 (in Chinese with English abstract)

[9] 李金才, 魏凤珍, 丁显萍. 小麦穗轴和小穗轴维管束系统及与 穗部生产力关系的研究. 作物学报, 1999, 25: 315-319

Li J C, Wei F Z, Ding X P. Relationship between vascular bundle system of rachis and rachilla and ear productivity. Acta Agron Sin, 1999, 25: 315-319 (in Chinese with English abstract)

[10] 徐正进, 陈温福, 曹洪任, 张龙步, 杨守仁. 水稻穗颈维管束 与穗部性状关系的研究. 作物学报, 1998, 24: 47-53

Xu Z J, Chen W F, Cao H R, Zhang L B, Yang S R. Relationship between the characters of panicle and vascular bundle in neck-panicle of rice. Acta Agron Sin, 1998, 24: 47-53 (in Chinese with English abstract)

[11] 刘仲发, 勾玲, 赵明, 张保军. 遮阴对玉米茎秆形态特征、穿 刺强度及抗倒伏能力的影响. 华北农学报, 2011, 26(4): 91-96 Liu Z F, Gou L, Zhao M, Zhang B J. Effects of shading on stalk morphological characteristics, rind penetration strength and lodging-resistance of maize. Acta Agric Boreali-Sin, 2011, 26(4): 
91-96 (in Chinese with English abstract)

[12] 崔海岩, 靳立斌, 李波, 张吉旺, 赵斌, 董树亭, 刘鹏. 遮阴对 夏玉米茎秆形态结构和倒伏的影响. 中国农业科学, 2012, 45: 3497-3505

Cui H Y, Jin L B, Li B, Zhang J W, Zhao B, Dong S T, Liu P. Effects of shading on stalks morphology, structure and lodging of summer maize in field. Sci Agric Sin, 2012, 45: 3497-3505 (in Chinese with English abstract)

[13] 李宁, 李建民, 翟志席, 李召虎, 段留生. 化控技术对玉米植 株抗倒伏性状、农艺性状及产量的影响. 玉米科学, 2010,18(6): 38-42

Li N, Li J M, Zhai Z X, Li Z H, Duan L S. Effects of chemical regulator on the lodging resistance traits, agricultural characters and yield of maize. J Maize Sci, 2010, 18(6): 38-42 (in Chinese with English abstract)

[14] 陈尚洪, 陈红琳, 沈学善, 王昌桃, 张玉兰, 刘定辉. 密度和 施氮量对丘陵区机播夏玉米产量及倒伏影响研究. 西南农业 学报, 2012, 25: 805-808

Chen S H, Chen H L, Shen X S, Wang C T, Zhang Y L, Liu D H. Effects of planting density and nitrogen application on yield and lodging of mechanized sowing summer maize. Southwest China J Agric Sci, 2012, 25: 805-808 (in Chinese with English abstract)

[15] Sakuratani T. Improvement of the probe for measuring water flow rate in intact plants with the stem heat balance method. J Agric Meteorol, 1984, 40: 273-277

[16] Baker J M, van Bavel C H M. Measurement of mass flow of water in the stems of herbaceous plants. Plant Cell Environ, 1987, 10: $777-782$

[17] Steinberg S L, van Bavel C H M, McFarland M J. A gauge to measure mass flow rate of sap in stems and trunks of woody plants. J Am Soc Hortic Sci, 1989, 114: 466-472

[18] 李会, 刘钰, 蔡甲冰, 毛晓敏. 夏玉米茎流速率和茎直径变化 规律及其影响因素. 农业工程学报, 2011, 27(10): 187-191 Li H, Liu Y, Cai J B, Mao X M. Change of sap flow rate and stem diameter micro variation of summer maize and influenct factors. Trans CSAE, 2011, 27(10): 187-191 (in Chinese with English abstract)

[19] 唐霞, 崔建垣, 岳祥飞, 王少昆, 岳广阳. 科尔沁沙地玉米茎 流变化规律研究. 水土保持通报, 2011, 31(2): 31-35

Tang X, Cui J Y, Yue X F, Wang S K, Yue G Y. Characteristics of maize sap flow in Horqin Sandy Land. Bull Soil Water Conserv, 2011, 31(2): 31-35 (in Chinese with English abstract)

[20] 岳广阳, 张铜会, 赵哈林, 牛丽, 刘新平, 黄刚. 科尔沁沙地 黄柳和小叶锦鸡儿茎流及蒸腾特征. 生态学报, 2006, 26: 3205-3213

Yue G Y, Zhang T H, Zhao H L, Niu L, Liu X P, Huang G. Characteristics of sap flow and transpiration of Salix gordejevii and Caragana microphylla in Horqin Sandy Land, Northeast China. Acta Ecol Sin, 2006, 26: 3205-3213 (in Chinese with English abstract)

[21] Westgate M E, Lizaso J, Batchelor W. Quantitative relationship between pollen-shed density and grain yield in maize. Crop Sci, 2003, 43: 934-942

[22] 熊飞, 孔妤, 孟秀荣, 陆巍, 马守宝, 王忠. 小麦穗部和颖果 维管束系统的发育解剖学研究. 麦类作物学报, 2009, 29: 93-99

Xiong F, Kong Y, Meng X R, Lu W, Ma S B, Wang Z. Study on vascular bundle system in spikes and caryopsis of wheat. Triticeae Crops, 2009, 29: 93-99 (in Chinese with English ab- stract)

[23] 裁昭峰, 方陈, 陈洪俭. 小麦节间的维管组织及其与单穗粒数 的关系. 作物学报, 1987, 13: 102-106

Qiu Z F, Fang C, Chen H J. On the vascular tissue of wheat internodal and its relationship to the grain number per spike. Acta Agron Sin, 1987, 13: 102-106

[24] 王铁固, 赵新亮, 马娟, 张怀胜, 陈士林. 种植密度对玉米产 量及主要农艺性状的影响. 广东农业科学, 2011, (23): 16-18

Wang T G, Zhao X L, M J, Zhang H S, Chen S L. Influence on main agronomic traits and yield of maize under different density. Guangdong Agric Sin, 2011, (23): 16-18 (in Chinese with English abstract)

[25] 周宇飞, 史振声, 吕德贵, 王艺陶, 王娜. 种植密度对不同耐 密性春玉米基部茎节维管束及根系伤流的影响. 西北植物学 报, 2013, 33: 518-526

Zhou Y F, Shi Z S, Lü D G, Wang Y T, Wang N. Effects of planting densities on basal stem vascular bundles and root bleeding sap of different density-tolerant maize cultivars. Acta Bot Boreal-Occident Sin, 2013, 33: 518-526 (in Chinese with English abstract)

[26] 荆彦辉, 徐正进, 王健林. 不同田间配置方式对水稻穗颈组织 的影响. 沈阳农业大学学报, 2003, 34: 355-357

Jing Y H, Xu Z J, Wang J L. Effects of different field collocation patterns on spike neck tissue in rice. J Shenyang Agric Univ, 2003, 34: 355-357 (in Chinese with English abstract)

[27] 孙红春, 李文芹, 刘连涛, 张永江, 李存东. 不同水分条件下 棉花主茎功能叶叶柄茎流速率的日变化规律. 华北农学报, 2012, 27(4): 218-222

Sun H C, Li W Q, Liu L T, Zhang Y J, Li C D. The diurnal variation law of cotton's main stem sap velocity at different moisture levels. Acta Agric Boreali-Sin, 2012, 27(4): 218-222 (in Chinese with English abstract)

[28] 李国臣, 于海业, 马成林, 王芯. 作物茎流变化规律的分析及 其在作物水分亏缺诊断中的应用. 吉林大学学报(理学版), 2004, 34: 573-571

Li G C, Yu H Y, Ma C L, Wang R. Diurnal variation of plant stem sap flow and its application in plant water deficiency diagnosis. J Jilin Univ (Sci Edn), 2004, 34: 573-571 (in Chinese with English abstract)

[29] 刘永红, 杨勤, 何文铸, 柯国华. 花期干旱和灌溉条件下植物 生长调节剂对玉米茎流和光合生理的影响. 西南农业学报, 2009, 22: 1305-1309

Liu Y H, Yang Q, He W Z, Ke G H. Effect of plant growth regulators on maize stem sap and photosynthesis under drought stress and irrigation at flowering stage. Southwest China J Agric Sic, 2009, 22: 1305-1309 (in Chinese with English abstract)

[30] 赵永玲, 刘钰, 蔡甲冰. 夏玉米茎流和茎直径变化规律及其关 系分析. 灌溉排水学报, 2010, 29(3): 24-28

Zhao Y L, Liu Y, Cai J B. The movements and relationships between the stem diameter variation and sap flow for summer maize. J Irrig Drainage, 2010, 29(3): 24-28 (in Chinese with English abstract)

[31] 龚道枝, 王金平, 康绍忠, 胡笑涛, 张富仓, 李志军. 不同水 分状况下桃树根茎液流变化规律研究. 农业工程学报, 2001, 17(4): 34-38

Gong D Z, Wang J P, Kang S Z, Hu X T, Zhang F C, Li Z J. Variations of stem and root sap flow of peach tree under different water status. Trans CSAE, 2001, 17(4): 34-38 (in Chinese with English abstract) 